\title{
Multi-year ACSM measurements at the central European research station Melpitz (Germany) - Part 1: Instrument robustness, quality assurance, and impact of upper size cutoff diameter
}

Laurent Poulain et al.

Correspondence to: Laurent Poulain (poulain@ tropos.de)

The copyright of individual parts of the supplement might differ from the CC BY 4.0 License. 


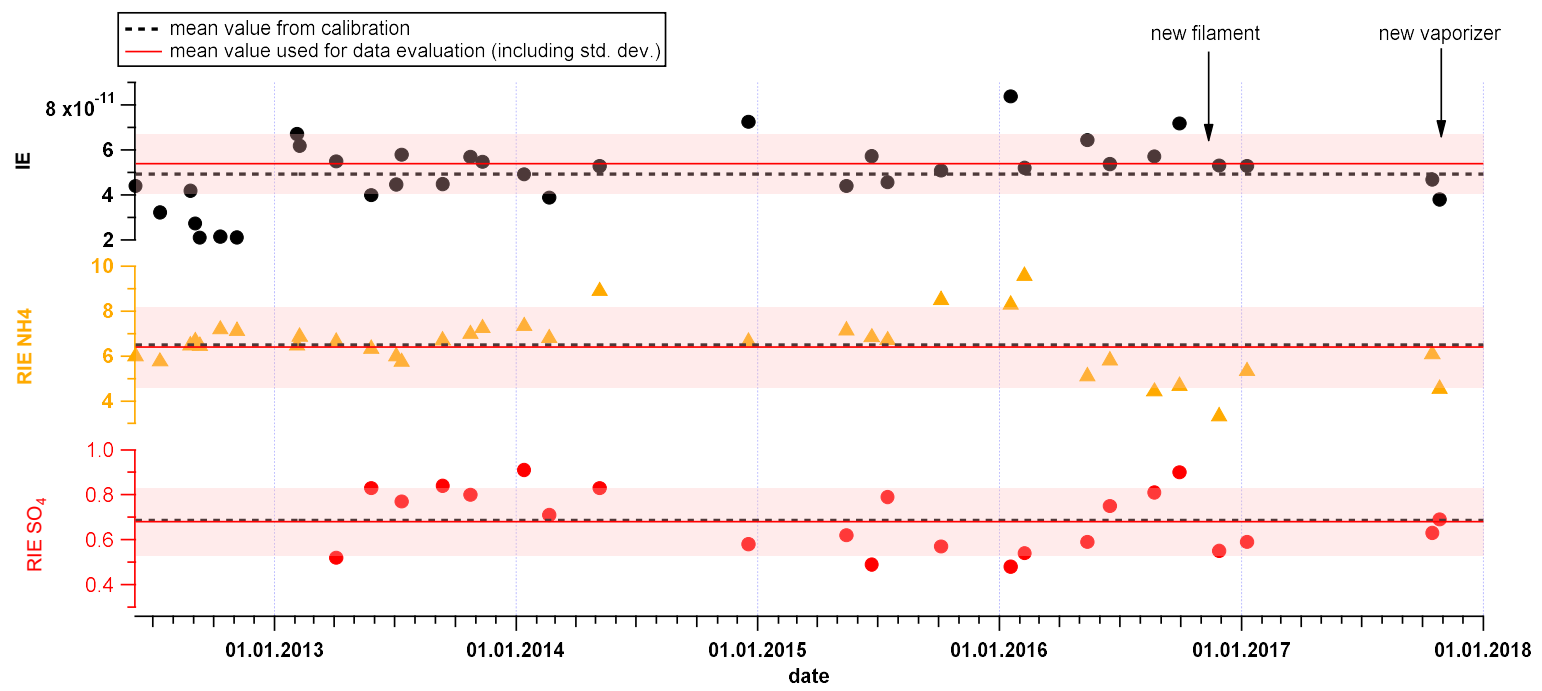

Figure S1. Time variation of the IE and RIE for ammonium and sulfate. The single points correspond to calibration, the dashed black line to the mean value from the calibration, and the full red line the mean value from the data analysis (shaded area corresponds to the standard 5 deviation). Major maintenance (change of filament and vaporizer) are including. 
Table S1. Fitting parameters of the comparison of the mass concentrations measured by the ACSM and offline $\mathrm{PM}_{1}$ considering the identified threshold $\mathrm{PM}_{1}: \mathrm{PM}_{2.5}<0.6$ or the entire $\mathrm{PM}_{1}$ dataset.

\begin{tabular}{|c|c|c|c|c|c|c|c|}
\hline \multirow[b]{2}{*}{ species } & \multirow[b]{2}{*}{ Time period } & \multicolumn{3}{|c|}{$\mathrm{PM}_{1}\left(\right.$ threshold $\left.\mathrm{PM}_{1}: \mathrm{PM}_{2.5}<0.6\right)$} & \multicolumn{3}{|c|}{$\mathrm{PM}_{1}$ no threshold } \\
\hline & & Slope & Intercept & $\mathrm{R}^{2}$ & Slope & Intercept & $\mathrm{R}^{2}$ \\
\hline \multirow[t]{5}{*}{ Total mass } & All dataset & 1.02 & -4.21 & 0.90 & 1.29 & -6.64 & 0.72 \\
\hline & Winter & 1.01 & -3.27 & 0.87 & 1.3 & -5.44 & 0.77 \\
\hline & Spring & 0.96 & -2.82 & 0.89 & 0.97 & -2.85 & 0.83 \\
\hline & Summer & 0.89 & -3.59 & 0.40 & 0.9 & -3.54 & 0.35 \\
\hline & Fall & 1.31 & -6.83 & 0.67 & 1.55 & -8.79 & 0.58 \\
\hline \multirow[t]{5}{*}{ Sulfate } & All dataset & 0.96 & -0.06 & 0.77 & 1.45 & -0.63 & 0.59 \\
\hline & Winter & 0.98 & -0.06 & 0.83 & 1.57 & -0.43 & 0.61 \\
\hline & Spring & 1.01 & -0.14 & 0.72 & 0.98 & -0.08 & 0.74 \\
\hline & Summer & 0.85 & 0.00 & 0.80 & 0.87 & -0.01 & 0.77 \\
\hline & Fall & 1.06 & -0.06 & 0.54 & 1.25 & -0.29 & 0.58 \\
\hline \multirow[t]{5}{*}{ Nitrate } & All dataset & 1.16 & 0.65 & 0.80 & 1.32 & 0.6 & 0.79 \\
\hline & Winter & 1.29 & 0.04 & 0.80 & 1.49 & -0.06 & 0.74 \\
\hline & Spring & 1.05 & 0.88 & 0.82 & 1.09 & 0.85 & 0.81 \\
\hline & Summer & 6.28 & -0.29 & 0.29 & 6.47 & -0.35 & 0.27 \\
\hline & Fall & 1.63 & 0.55 & 0.51 & 1.9 & 0.39 & 0.56 \\
\hline \multirow[t]{5}{*}{ Ammonium } & All dataset & 1.14 & -0.05 & 0.77 & 1.40 & -0.21 & 0.71 \\
\hline & Winter & 1.02 & 0.08 & 0.83 & 1.36 & -0.09 & 0.65 \\
\hline & Spring & 1.15 & -0.02 & 0.79 & 1.15 & -0.01 & 0.80 \\
\hline & Summer & 1.47 & -0.37 & 0.49 & 1.53 & -0.39 & 0.51 \\
\hline & Fall & 1.74 & -0.31 & 0.44 & 2.01 & -0.49 & 0.46 \\
\hline \multirow[t]{5}{*}{ Organic $\left(\mathrm{OM}_{\mathrm{ACSM}}\right)$} & All dataset & 1.71 & 0.11 & 0.68 & 1.85 & -0.1 & 0.74 \\
\hline & Winter & 1.29 & 0.28 & 0.78 & 1.70 & -0.29 & 0.76 \\
\hline & Spring & 1.84 & 0.02 & 0.81 & 1.89 & -0.1 & 0.79 \\
\hline & Summer & 2.74 & -1.44 & 0.68 & 2.83 & -1.58 & 0.66 \\
\hline & Fall & 2.49 & -1.07 & 0.69 & 2.41 & -1.06 & 0.67 \\
\hline
\end{tabular}




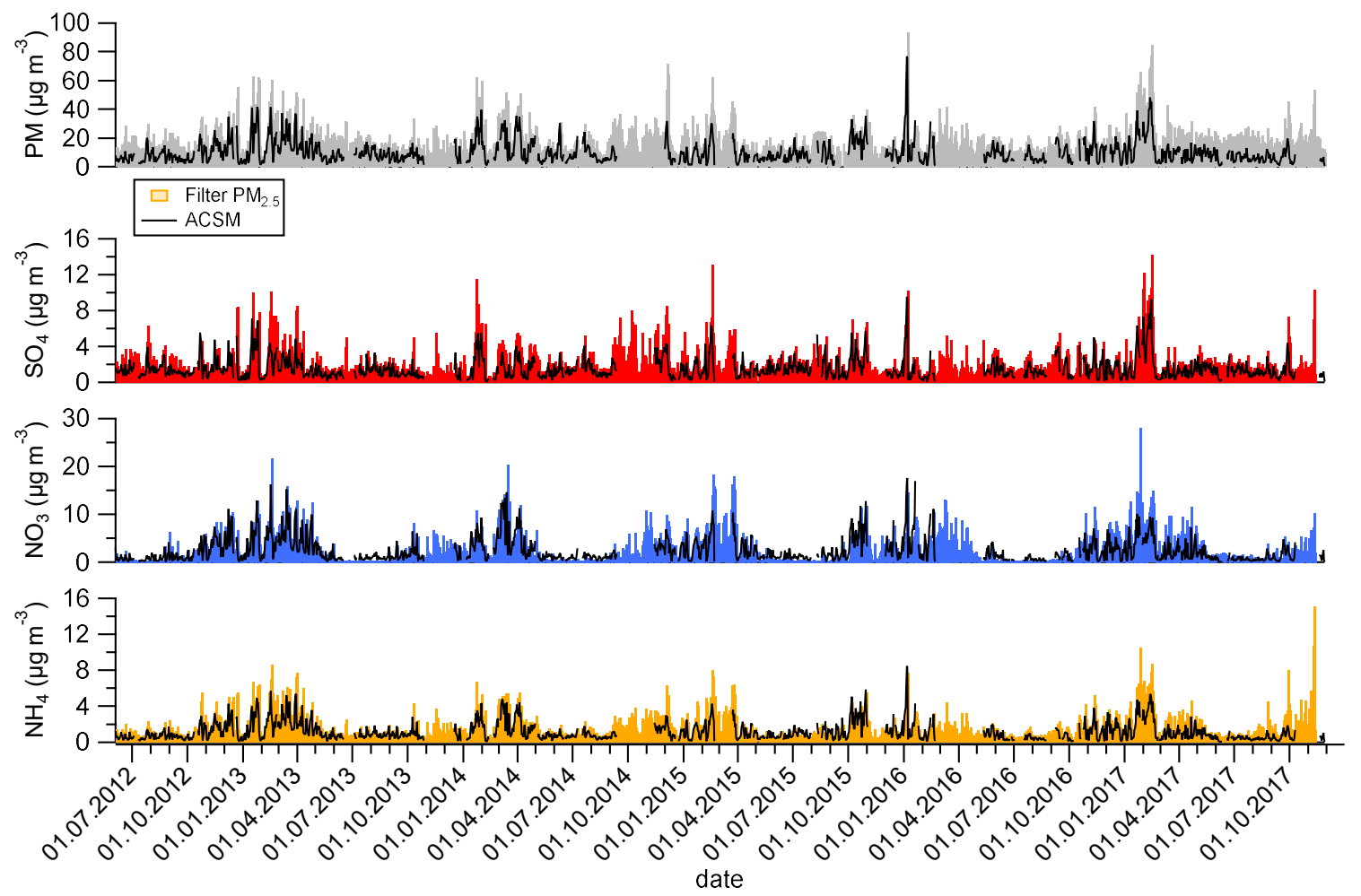

Figure S2. Time series ACSM (daily average, black line) and daily 24 h $\mathrm{PM}_{2.5}$ filter samples (colored bars) for the total mass, sulfate, nitrate, and ammonium. The particulate matter (PM) corresponds to the sum of ACSM species and $\mathrm{EBC}_{\mathrm{PM} 1}$ for the online instrument and the filter mass for the offline samples. 

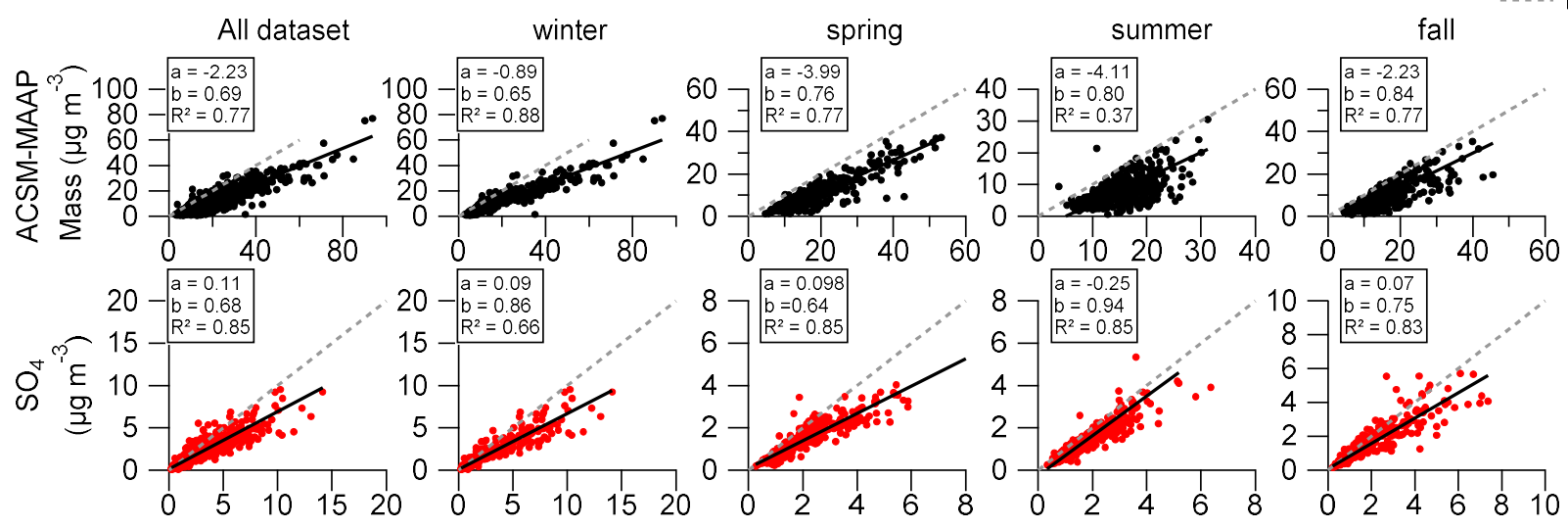

line1:1
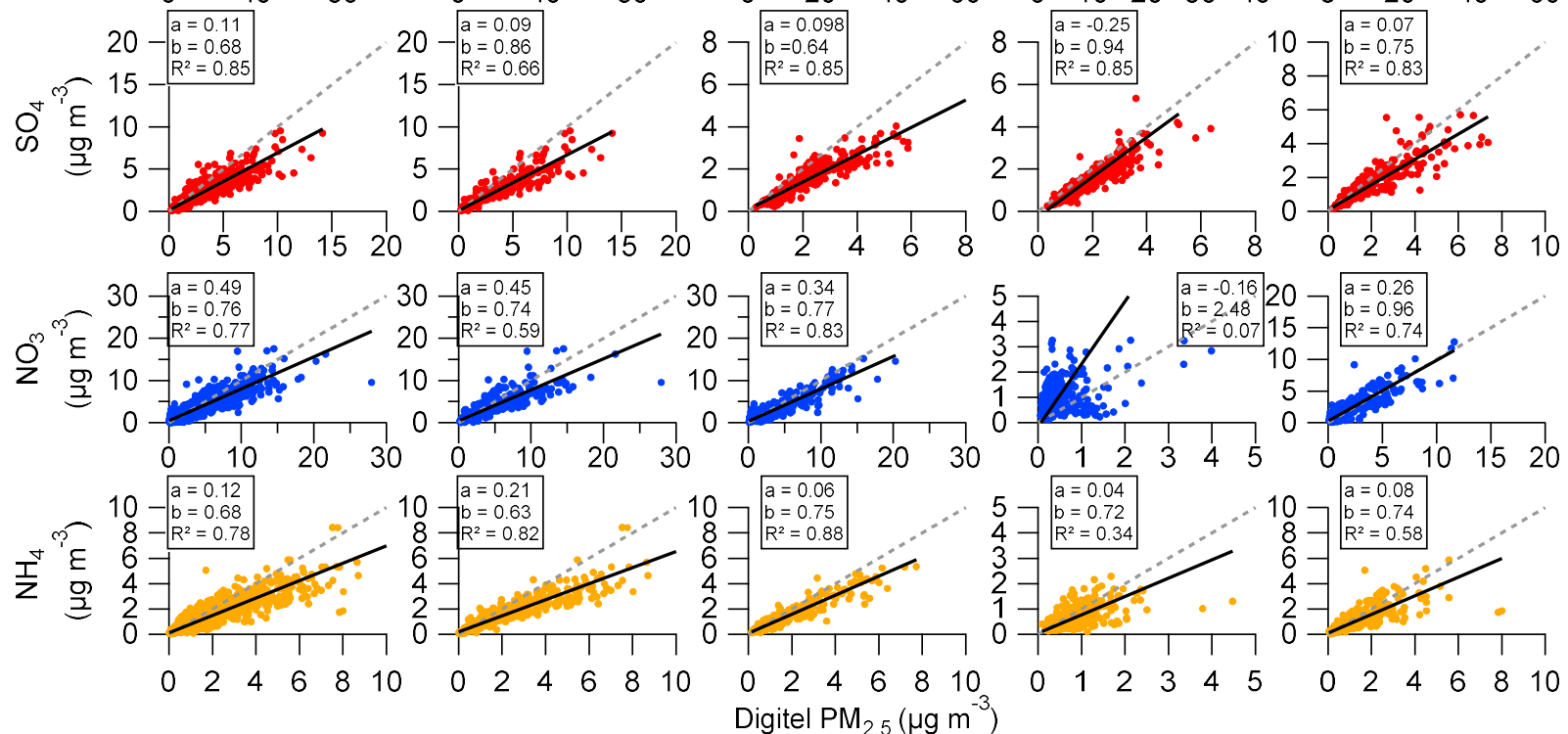

Figure S3. Scatter plot of the ACSM species mass concentration measurements compared to corresponding daily $\mathrm{PM}_{2.5}$ mass concentration over the entire period and seasonality. 

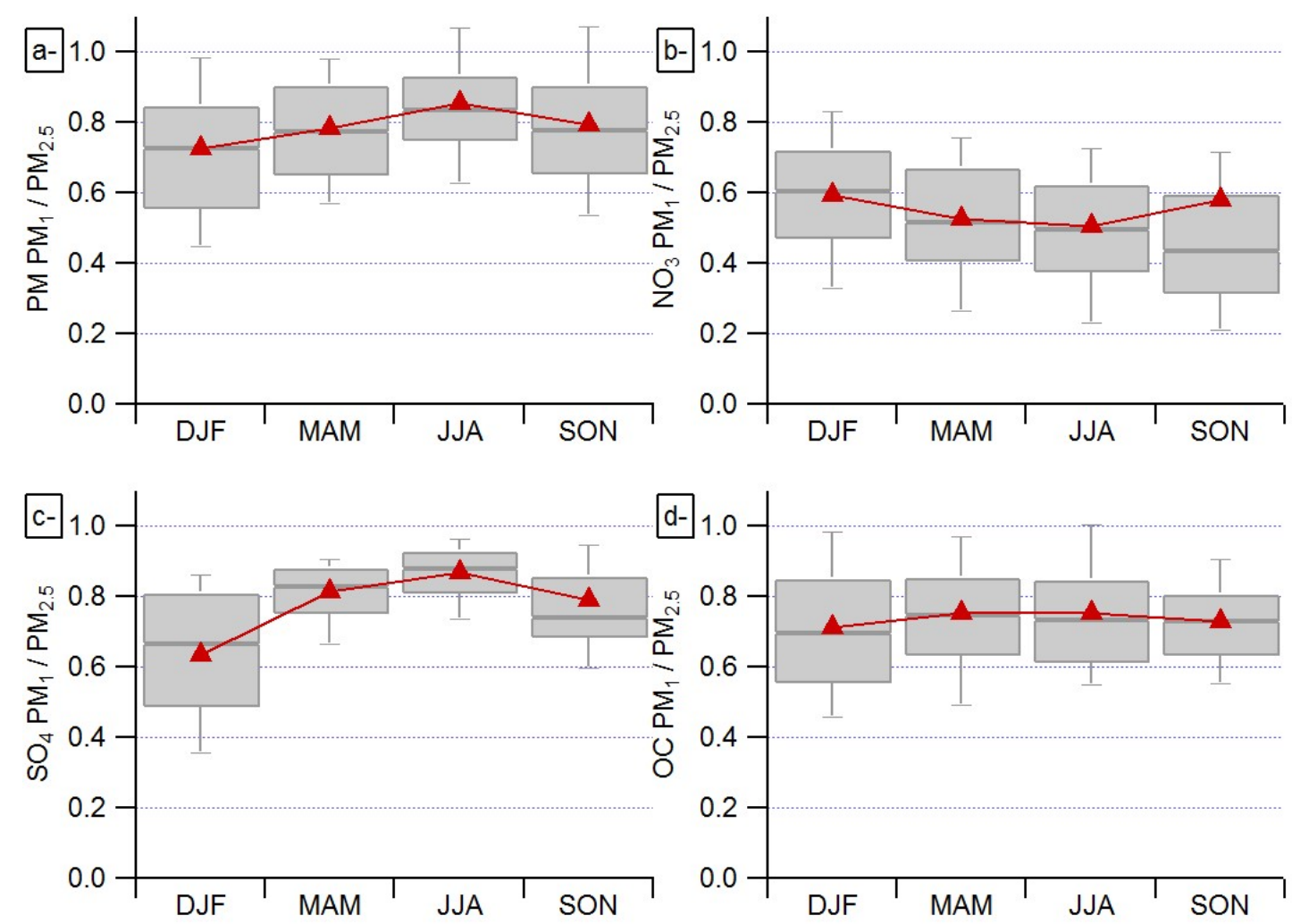

Figure S4. Seasonal variability of the $\mathrm{PM}_{1}: \mathrm{PM}_{2.5}$ ratios of total $\mathrm{PM}(\mathrm{a})$, nitrate (b), sulfate (c) and OC (d). 

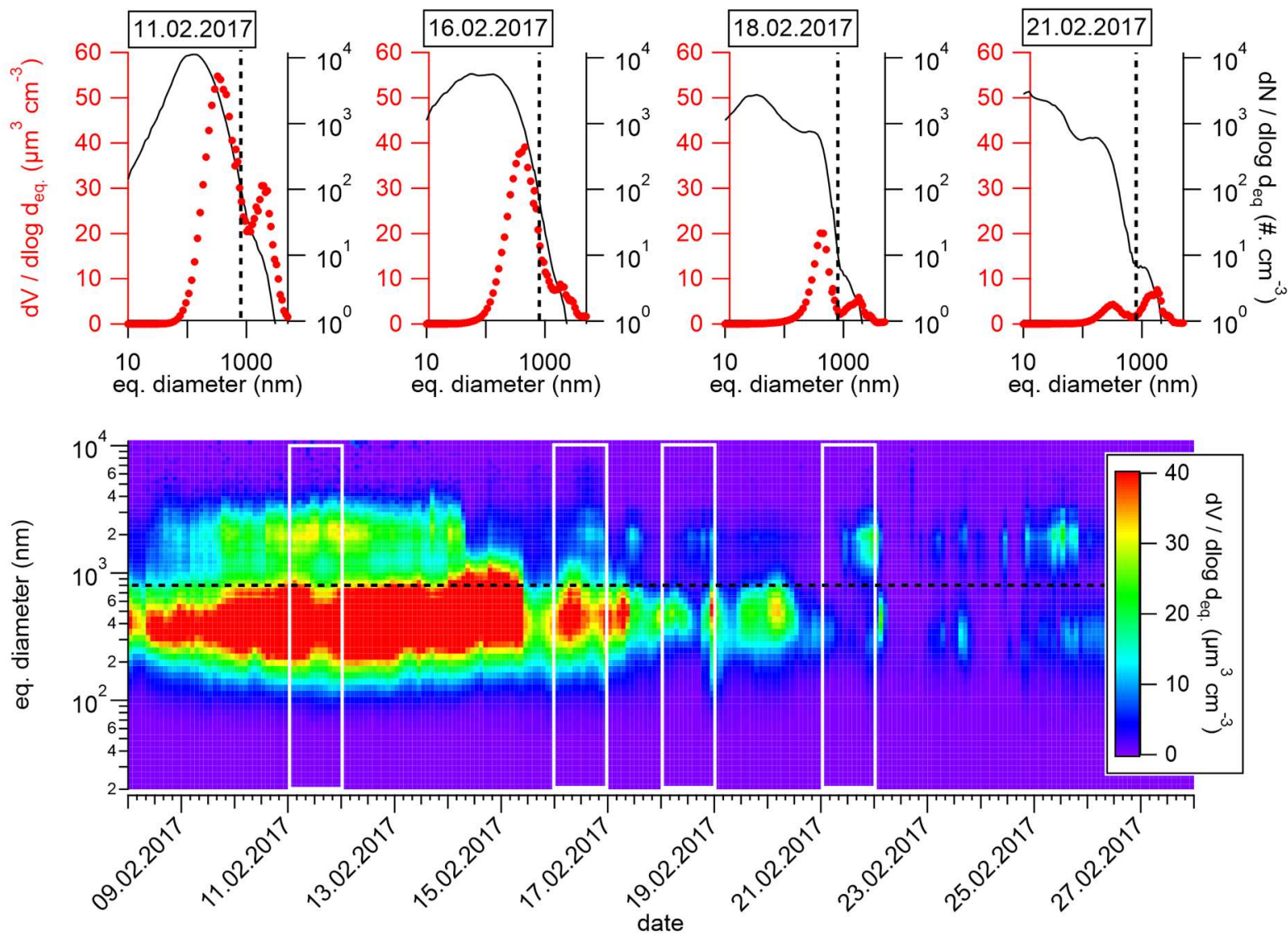

Figure S5. Influence of coarse mode particles on particle number and volume size distribution in the range 10 to $5000 \mathrm{~nm}$ obtained by merging MPSS and APSS (assuming spherical particle and a constant density of 1.6). The top panels represent the daily median particle number (black full line) and volume (red dots) size distribution for selected days emphasized by the white box on the particle volume size distribution from February 2017. The dashed black lines on the plots indicate the upper size bin of the MPSS. 


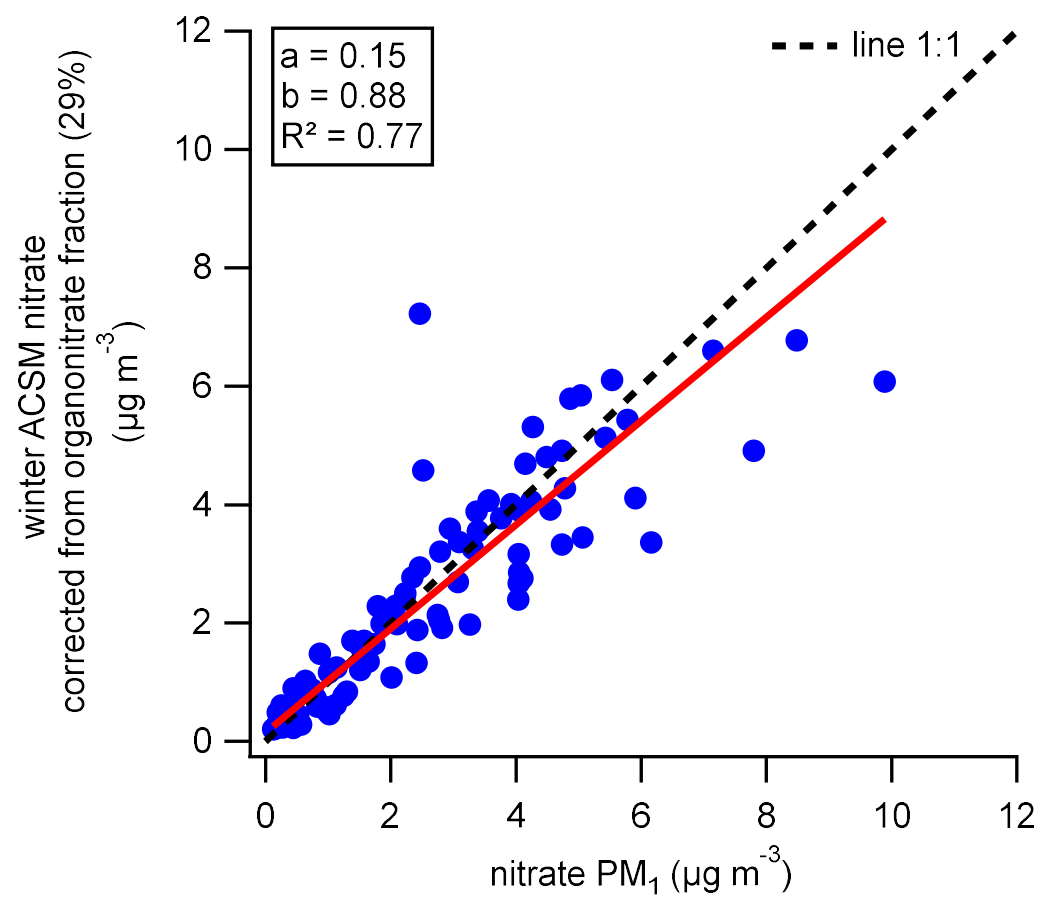

Figure S6. Scatter plot of the winter (DJF) ACSM nitrate mass concentration corrected for organo-nitrate contribution during days with a $\mathrm{PM}_{1}: \mathrm{PM}_{2.5}<0.6$ compared to $\mathrm{PM}_{1}$ nitrate mass concentration. The linear regressions (red lines) were calculated using the least orthogonal distance fit method.
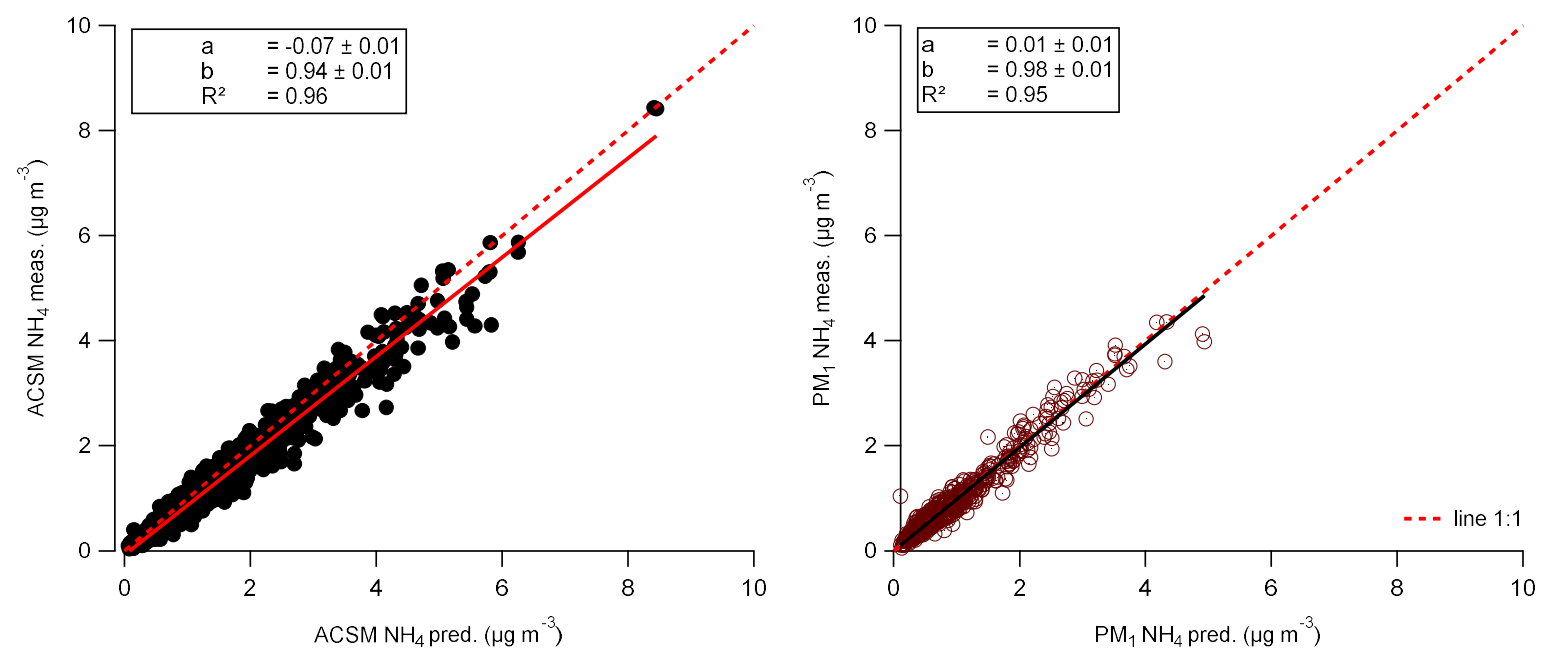

Figure S7. Comparison of the measured ammonium with the predicted ammonium mass concentration for the ACSM (left) and offline PM samples assuming a full neutralization by nitrate, sulfate, and chloride. The linear regressions were calculated using the least orthogonal 10 distance fit method $(\mathrm{y}=\mathrm{ax}+\mathrm{b})$. 


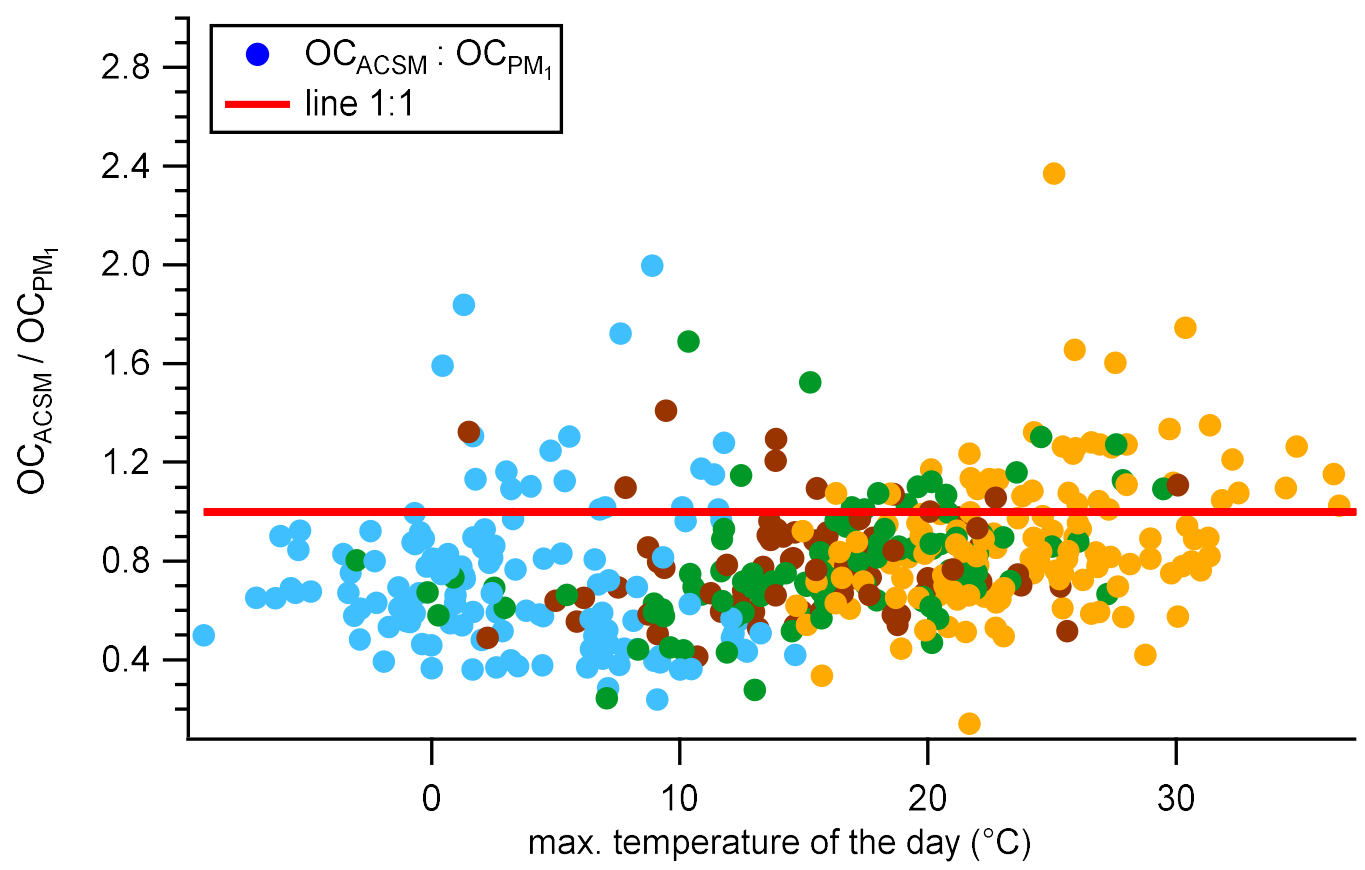

Figure S8. Influence of the maximum day temperature to the $\mathrm{OC}_{\mathrm{ACS}}: \mathrm{OC}_{\mathrm{PM} 1}$ ratio.

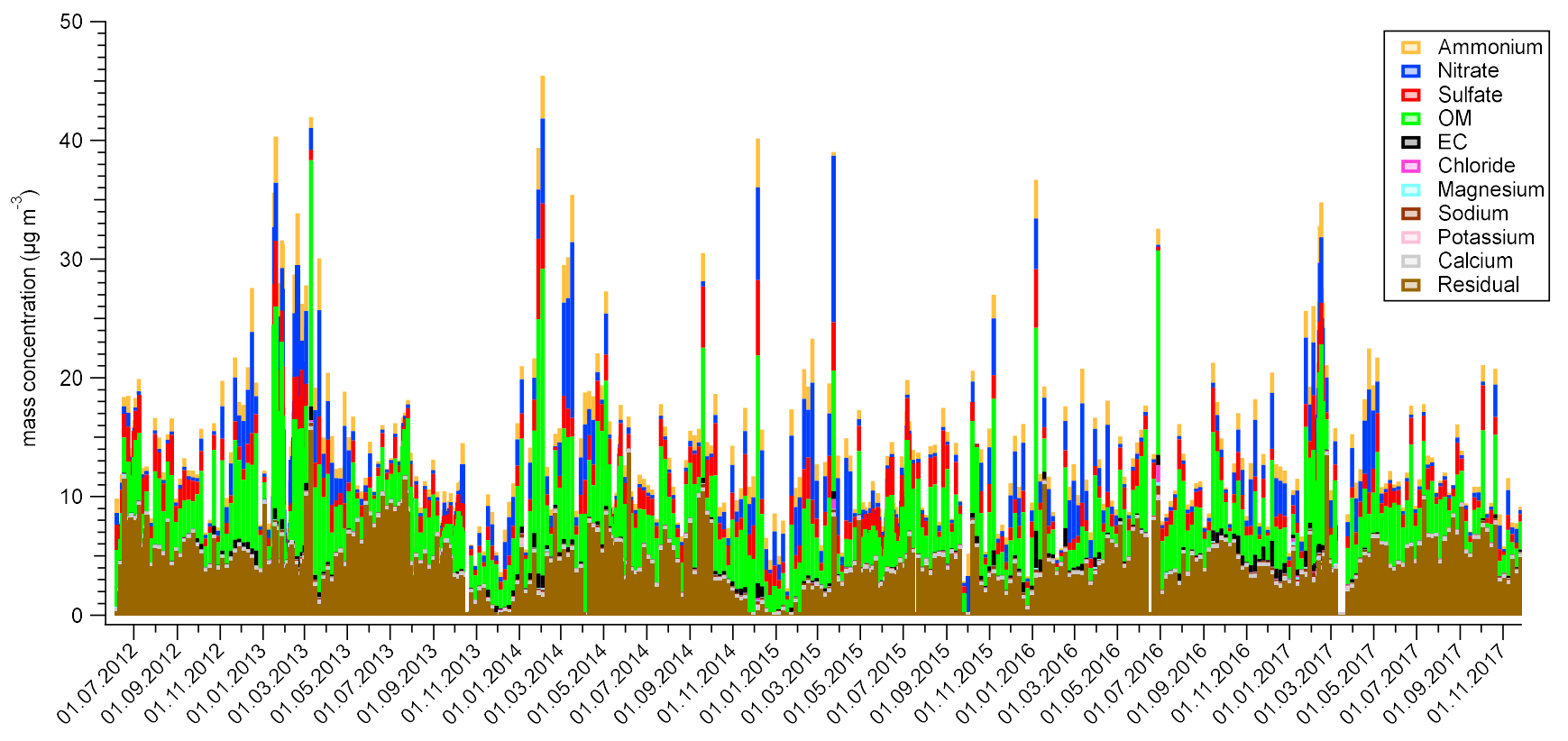

date

5 Figure S9. Time series of the Digitel PM1 chemical composition. Conversion of OC into OM was made based on the seasonal OM:OC ratio presented in Figure 6. 